\title{
Different extracting methods of medicinal herbs
}

\author{
Krenaida Taraj ${ }^{1}$ \\ Email: krenaida.taraj@fshn.edu.al
}

${ }^{1}$ Albanian University, Faculty of Medicinal Sciences, Department of Pharmacy

Received: October 3, 2021

Received in revised: October 21, 2021

Accepted: November 4, 2021

\begin{abstract}
Albania is a well-known country for the diversity and exports of medicinal and aromatic plants. Sage is one of the most popular plants that is exported in USA and in other different countries, due to its scientific and medicinal effects in human body. Sage and its essential oil have been known since the ancient times to be used for the treatment of seizure, ulcers, tremor, hyperglycemia, diabetes, diarrhea, paralysis, etc. According to recent studies sage does not have currently any medical uses but some studies are enthusiast for its use in Alzheimer disease. In this work, essential oil of sage leaves has been obtained with different methods of extraction such as, liquid $\mathrm{CO}_{2}$ extraction, water distillation method and organic solvent extraction. The essential oil of sage leaves carried out by different extraction methods used in this study, is then characterized with thin layer chromatography. It is obvious from the displayed results that the yield of the extract attained using the near critical conditions (liquid $\mathrm{CO}_{2}$ ) is higher than the yield acquired by reflux distillation using hexane as a solvent. In this context, it is relevant to note that in comparison to hexane, carbon dioxide $\left(\mathrm{CO}_{2}\right)$ is the most extensively used solvent in fluid extractions, as it is physiologically harmless, environmentally safe, and it can be easily removed from products. This is a good result and very important for its uses in pharmaceutical purposes.
\end{abstract}

Keywords: Salvia Officinalis, Essential Oil, $\mathrm{CO}_{2}$ Extraction, Hexane Extraction, Thin Layer Chromatography

\section{Introduction}

Albania is distinguished for its biological diversity and it is a large manufacturer of aromatic plants such as Salvia officinalis L., chamomile, thyme, balsam flower (Hypericum perforatum), spearmint (Mentha spicata L.) etc (Taraj, 2020; Taraj et al., 2013; Asllani, 2002). Today, it is known that all essential oils of aromatic and medicinal plants are used extensively in detergents, soaps, cosmetics, pharmaceuticals, perfumes and in confectionery food products. Salvia officinalis L. has big flowers, in blue-violet color (Asllani, 2002). The leaves of Salvia officinalis L. contain essential oil (1-2.5\%) (Taraj, 2020) and the main constituents are monoterpens, sesquiterpens (thujone $(\alpha, \beta)$, camphor, borneol etc.). Additionally, the main components of essential oil of Salvia officinalis L. plant are thujone (40 - 50\%). Pharmaceutical preparations of Salvia officinalis L. are used in different therapies, for example treatments of herpes, anxiety, or throat infections etc. In addition, essential oil Salvia officinalis L. has bacteriostatic and bactericidal action against Bacillus cereus and Bacillus subtilis. The most common methods used for obtaining essential oils are water distillation method, distillation with organic solvents method and extraction with liquid $\mathrm{CO}_{2}$ (under pressure) method (Taraj, 2020; Taraj et al., 2013; Asllani, 2002). The latter is based on the extraction of essential oil from the inner parts of cells onto the surface of the plant. In the present work the essential oil of Salvia Officinalis L (leaves) is obtained by hexane distillation and $\mathrm{CO}_{2}$ extraction $\left(40^{\circ} \mathrm{C}\right)$

Copyright @ 2021, Journal of Asian Multicultural Research for Economy and Management Study, Under the license CC BY-SA 4.0 
methods. The obtained fractions are characterized by thin layer chromatography by means of a standard compound (Çullaj, 2005; Koch, nd). The aim of the current work is to present two complementary methods for extracting essential oils from the leaves of Salvia officinalis L. and further characterize the obtained extracts by thin layer chromatography. Additionally, advantages and disadvantages of the methods used for the extractions are indicated as well

\section{Methods}

Sage leaves are dried at $40^{\circ} \mathrm{C}$ and then grounded as finely as possible to be suitable for extraction experiments. Also the leaves have been cleaned by various impurities that may have had during their collection.

Extraction by means of $\mathrm{CO}_{2}$ solvent: The experiment with liquid $\mathrm{CO}_{2}$ was conducted in an autoclave, as formerly reported $[1,2]$ by means of a Soxhlet recipient (Soxhlet technique). The extraction occurs in vapor-liquid equilibrium $\left(\mathrm{T}=31.1^{\circ} \mathrm{C}\right.$ and $\left.\mathrm{P}=73.8 \mathrm{bar}\right) . \mathrm{CO}_{2}$ is a good solvent for liquids (Taraj, 2020). Under critical conditions $\left(\mathrm{T}=40^{\circ} \mathrm{C}, \mathrm{P}_{\mathrm{CO} 2}=58\right.$ bar) $\mathrm{CO}_{2}$ exhibits properties between those of a liquid and gas.

Extraction by means of hexane solvent: A reflux distillation set up was used, consisting of a cooling system, a condenser, a $2000 \mathrm{ml}$ flask and a heating plate. The amount of the plant used was $100 \mathrm{~g}$ dispersed in $1000 \mathrm{ml}$ hexane. The distillation continued for four hours. After filtration was carried out, the solvent was removed using a rotary evaporator.

Thin layer chromatography (TLC): The obtained extracts were characterized by TLC. It is a fast method and has a good resolution and high sensibility. It is reported that for the current conditions used in this work, $R_{f}$ is characteristic for a single component (Çullaj, 2005). The separation of essential oil in fractions is based on Britannic method of Pharmacopoeia 2007 which includes the test of vanillin ( $1 \%$ vanillin in alcohol $\mathrm{V} / \mathrm{V}$, adding $2 \mathrm{ml} \mathrm{H}_{2} \mathrm{SO}_{4} \mathrm{cc}$ ), as identification reagent of compounds containing oil extracts of Salvia officinalis L. (Farmacopea ufficiale della Republica Italiana, 1981; British Pharmacopoeia, 2007).

\section{Results and Discussion}

The overall results of the extracts obtained by the two different extracting methods are presented in table 1 . The extract obtained by means of liquid $\mathrm{CO}_{2}$ was yellow (yellow crystals), whereas in the case of the extraction carried by means of hexane, the acquired extract was green-brown in color (jellylike-gelatinous). It is obvious from the displayed results that the yield of the extract attained using the near critical conditions (liquid $\mathrm{CO}_{2}$ ) is higher than the yield acquired by reflux distillation using hexane as a solvent. In this context, it is relevant to note that in comparison to hexane, carbon dioxide $\left(\mathrm{CO}_{2}\right)$ is the most extensively used solvent in fluid extractions, as it is physiologically harmless, environmentally safe, and it can be easily removed from products (Taraj, 2020)

Table 1. Experimental data for the $\mathrm{CO}_{2}$ extraction at $40^{\circ} \mathrm{C}\left(\mathrm{P}_{\mathrm{CO} 2}=58\right.$ bar $)$ and hexane extraction (reflux distillation).

\begin{tabular}{|c|c|c|}
\hline & Extraction by CO & \\
\hline Amount of leaves (g) & Amount of extract (g) & Yield (\%) \\
\hline 8.64 & 0.2 & 2.3 \\
\hline & & \\
\hline & Extraction by hexane & \\
\hline Amount of leaves (g) & Amount of extract (g) & Yield (\%) \\
\hline 100 & 27.61 & 5.64 \\
\hline
\end{tabular}


Moreover, the chemical composition of the extracts was determined by thin layer chromatography. Fig. 1 represents chromatographic silica gel plates of the standard 1-8 cineole (eucalyptol) (indicated by $\mathbf{A}$ in Fig. 1) used and of the essential oil of the extract obtained by liquid $\mathrm{CO}_{2}$ (indicated by $\mathbf{B}$ in Fig. 1). As eluent was used a mixture of toluene: ethyl acetate $(5: 1 \mathrm{~V} / \mathrm{V})$ and as identification reagent was used vanillin (Farmacopea ufficiale della Republica Italiana, 1981; British Pharmacopoeia, 2007).

A

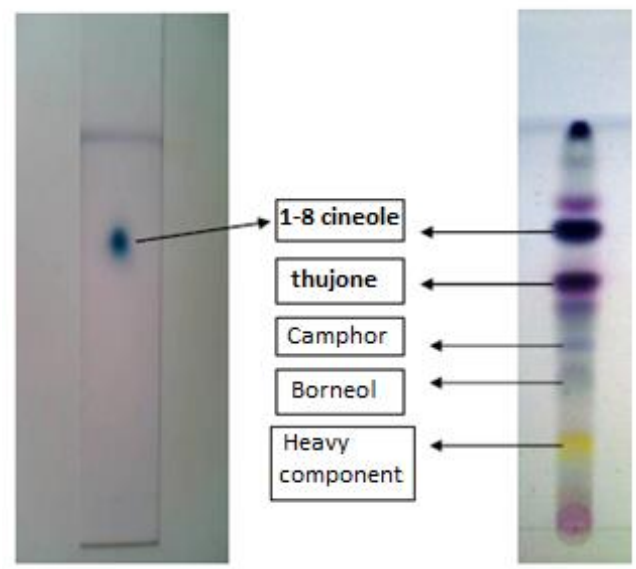

Figure 1. Chromatographic silica gel plate $10 \times 20 \mathrm{~cm}^{2}$ and $5 \times 20 \mathrm{~cm}^{2}$ of : A- standard cineol (eucalyptol) $30 \mu \mathrm{l}$ in $20 \mathrm{ml}$ alcohol (ethanol) and B- essential oil obtained by $\mathrm{CO}_{2}$ extraction.

The constituents present in the essential oil are indicated by arrows in Fig. 1. These constituents are identified based on their $\mathrm{R}_{\mathrm{f}}$ values Farmacopea ufficiale della Republica Italiana, 1981; British Pharmacopoeia, 2007. Additionally, Fig. 2 displays the composition of oil extracts obtained by liquid $\mathrm{CO}_{2}$ solvent (A) and by hexane distillation (B).

A

B

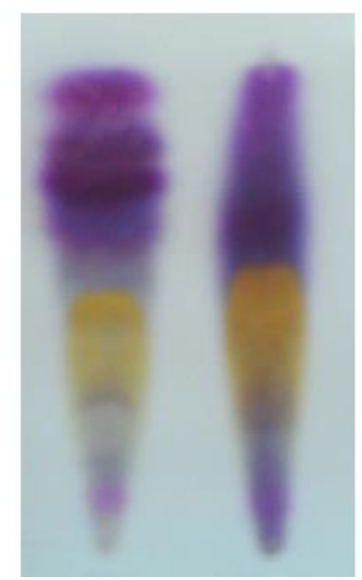

Figure 2. Chromatographic silica gel plates $10 \times 20 \mathrm{~cm}^{2}$ and $5 \times 20 \mathrm{~cm}^{2}$ for the extracts obtained by liquid $\mathrm{CO}_{2}(\mathrm{~A})$ and by hexane (B).

It is observed from the chromatograms in Fig. 1 and 2 that extracting solvents, carbon dioxide and hexane are able to extract from the sage leaves numerous constituents. Moreover, the color of the spots indicates the presence of the same components in both extracts. Finally, Fig. 3 displays an overview of the spots observed on the Si plate for the extract obtained by liquid carbon dioxide (A) and fractions (6 different droplets) taken from the oil extract obtained by liquid $\mathrm{CO}_{2}$. It is obvious from the chromatogram in Fig. 3 that the constituents present in the extract can be separated. 


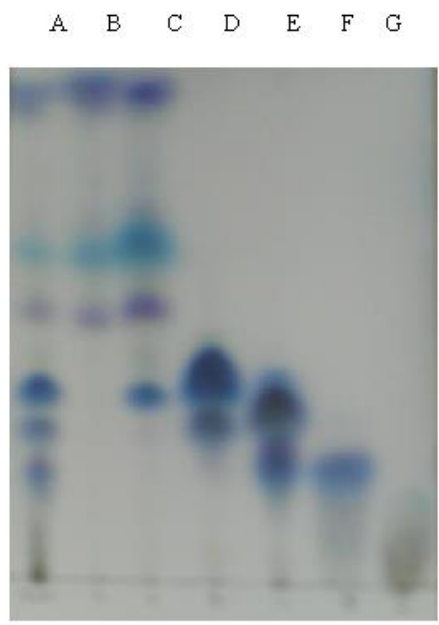

Figure 3. Chromatographic silica gel plate of the extract obtained by liquid $\mathrm{CO}_{2}(\mathrm{~A})$ and 6 droplets $(\mathrm{B}, \mathrm{C}, \mathrm{D}, \mathrm{E}, \mathrm{F}, \mathrm{G})$ taken from the extract obtained by liquid $\mathrm{CO}_{2}$ as well (fractions). The eluent used was hexane.

Additionally, the identification of the spots on chromatograms was done by comparing the colored spot of the standard component with the colored spots of the extracts and their $\mathrm{R}_{\mathrm{f}}$ respective values. Table 2 indicates the $R_{f}$ respective values and the colored spots on chromatograms according to BP 2007 (British Pharmacopoeia, 2007)

Table $2 . \mathrm{R}_{\mathrm{f}}$ respective values and the colored spots on the silica plates British Pharmacopoeia (2007).

\begin{tabular}{|c|c|c|}
\hline Components & The color of spots & Respective $\mathbf{R}_{\mathbf{f}}$ values \\
\hline $1-8$ cineole & blue-green & 0.68 \\
\hline$\alpha$ - thujone & violet & 0.56 \\
\hline camphor & pink -violet & 0.46 \\
\hline borneol & green & 0.39 \\
\hline
\end{tabular}

\section{Conclusion}

In this scientific work, the essential oil of sage leaves was obtained using two complementary methods: liquid $\mathrm{CO}_{2}$ extraction (soxhlet method) and extraction by reflux distillation using hexane as solvent. Both methods proved to be successful, however the yield of the extract obtained by liquid $\mathrm{CO}_{2}$ was higher. TLC indicated presence of many components identifying several of them as well. Both methods revealed also the presence of the same components. Separation of the constituents was also possible.

\section{References}

Asllani, U., (2002). Essential oil of aromatic and medicinal plants of Albania, Tirana: Albania

British Pharmacopoeia (2007). CD-ROM, Monographs: Medicinal and Pharmaceutical substances Sage leaf -Salvia officinalis - Oral

Çullaj, A. (2005). Instrumental methods of chemical analyses (2), Tirana: Albania.

Farmacopea ufficiale della Republica Italiana (1981). Droge vegetali e preparacione 4(6), 296304.

Koch, A., Basar, S., Richter, R., in: M. (nd) Waksmundzka-Hajnos, J. Sherma, T. Kowalska (eds.), Thin Layer Chromatography in Phytochemistry, Vol. 99 of the Chromatographic Science Series, CRC Press, Boca Raton. 
Taraj, K., (2020). Surface characterization of medicinal plants before and after extraction by subcritical $\mathrm{CO}_{2}$, (Thesis), Department of Chemistry, Faculty of Natural Sciences, University of Tirana, Tirana, Albania (in Albanian language).

Taraj, K., Delibashi, A., Andoni, A., Lazo, P., Kokalari, Teli E., Lame, A., Xhaxhiu, K., Çomo, A., (2013). Extraction of chamomile essential oil by subcritical $\mathrm{CO}_{2}$ and its analysis by UV-VIS spectrophotometer. Asian J. Chem. 25, 7361-7364. 